\title{
Social Security and Saving: A Comment
}

\author{
Dennis Coates \\ Brad Humphreys \\ Department of Economics \\ $\mathrm{UMBC}$ \\ 1000 Hilltop Circle \\ Baltimore, MD 21250
}

September 17, 1997

We thank our colleague Bill Lord, two anonymous reviewers and Joel Slemrod for their comments on this paper. It is stronger for their efforts. Any remaining defects are our responsibility. 


\begin{abstract}
This paper estimates an aggregate consumption function to test the robustness of Feldstein's conclusions regarding the effects of Social Security wealth on aggregate savings. Our approach differs from other criticisms of Feldstein's analysis in two ways. First, we test for nonlinearity in the impact of wealth on consumption and for the difference in impacts across Social Security wealth and all other wealth. The Feldstein model of linear but unequal impacts across types of wealth is rejected by the data. Second, we account for recent advances in the theoretical underpinnings of the consumption function and in the empirical implementation of those advances. Using either approach, we find that the marginal impact of Social Security and all other wealth has risen during the post-war era. However, only in recent years has the marginal impact been close to Feldstein's estimate of 2.9 cents of lost savings on an extra dollar of wealth.
\end{abstract}


Martin Feldstein (1996) has presented evidence that the Social Security program induces a reduction in savings to the tune of $\$ 416$ billion in 1992 , about $60 \%$ of total savings, a figure similar to the one he found over twenty years ago (Feldstein, 1974). This evidence suggests that Social Security has a substantial impact on the level of aggregate savings and on the capital stock in the United States. The clear, if implicit, policy implication is that Social Security should be reduced so as to induce greater savings and greater growth. In this comment on Feldstein (1996) we show that reasonable alternative specifications of the consumption function yield much smaller impacts of Social Security on savings.

First, Feldstein's approach allows household wealth and Social Security wealth to have differing impacts on consumption. Micro level evidence indicates that the marginal propensities to consume out of different types of wealth vary substantially (Thaler, 1990; Browning and Lusardi, 1996). So imposing different effects may be justified on these grounds. However, given the aggregation of all non-Social Security wealth into a single variable, it is not clear that Social Security wealth will have a marginal impact different from that of what is essentially a weighted average of the effects of the other components of wealth. We test the implicit restriction that Social Security wealth has a marginal impact different from the average marginal propensity to consume across types of wealth.

Second, Feldstein implicitly equates marginal and average impact. His regression analysis clearly estimates the effect of an additional dollar of per capita Social Security wealth on per capita consumption. His estimated coefficient on Social Security wealth is .029; an additional dollar of Social Security wealth per capita leads to an additional 2.9 cents of consumer spending per capita. Feldstein uses this figure to calculate the total effect of Social Security wealth, estimated at $\$ 14,246$ billion (1992 dollars) in 1992, on consumption. While the average and marginal impacts could be the same, the literature on precautionary savings suggests they should differ. Uncertainty in the Social Security wealth implies that the marginal propensity to consume from such wealth and the level of that wealth should rise together. Our results show exactly this effect. 
There are at least two reasons to allow the data to indicate whether the marginal impact is constant or variable. First, a non-linear underlying model estimated using a linear approximation leads to biased and inconsistent point estimates; the extent of the bias is unknown making the use of .029 questionable. Second, a declining or rising marginal impact implies different effects on saving than a constant marginal impact. At present, Social Security wealth is rising as the trust funds are increased in anticipation of the retirement of the baby-boom generation. If average and marginal impacts are equal, and declining in wealth, then the impact of Social Security wealth on savings should be falling. That is, the amount of savings "lost" due to a small increase in Social Security wealth in a given year must be getting smaller. If the marginal impact is rising, then the effect of Social Security wealth on savings is getting larger; more savings is being lost on each dollar of increase in the trust funds than was lost on earlier accumulation of Social Security wealth.

Finally, common overlapping generations models suggest that the marginal propensity to consume out of assets depends upon the age distribution in the population. The Feldstein specification does not account for this possibility; we estimate a model which does. As individuals approach retirement, the uncertainty surrounding legislated net of tax benefits declines. Thus, as the population has aged, aggregate Social Security wealth has become more certain and the marginal propensity to consume from it should have risen. Our results are also consistent with this effect.

The results of our tests lead us to conclude that the Feldstein analysis is not robust to reasonable alternative specifications of the consumption function. Moreover, tests of these other specifications against the Feldstein equation reject his model. There is no empirical support in this data for the constant marginal impact of Social Security wealth. Nor does the data support different marginal impacts of Social Security wealth and other household wealth in a linear model specification. Finally, the data prefer the specification which allows the marginal propensity to consume out of assets to depend upon the age distribution of the population. 
The paper is organized as follows. The next section places the results presented in Feldstein (1996) in the context of the continuing debate on the effects of Social Security wealth on aggregate savings and suggests theoretical reasons for non-constant marginal impacts of wealth. Section three reports our regression analysis and examines the marginal impact of Social Security wealth on consumption over time. Section four concludes the discussion.

\section{Literature and critique}

In 1974, Martin Feldstein published a study of the overall impact of the Social Security system on aggregate savings and capital accumulation. He argued that the presence of Social Security Wealth has two effects on household savings decisions. First, households would substitute savings forced upon them by the Social Security program for planned personal savings, reducing personal savings. On the other hand, the additional wealth engendered by Social Security would induce individuals to retire earlier than otherwise, leading to higher lifetime savings and a larger pool of wealth to draw upon during a longer planned retirement; this induced retirement effect increases personal savings. Consequently, Feldstein concluded that the ultimate impact of the Social Security system on aggregate private savings was an empirical question.

Feldstein's empirical model was based on a general "life cycle" framework similar to the one used by Ando and Modigliani (1963). Feldstein specified aggregate consumption (C) as a function of current and lagged disposable income (YD), retained earnings (RE), the rate of unemployment (U), household wealth other than from Social Security (W), and Social Security wealth (SSW). Key to the analysis is the measurement of Social Security wealth. Feldstein devoted considerable effort and attention to constructing an estimate of this variable and provided substantial details on this process.

His estimates show that Social Security wealth has a significant impact on consumption; current and lagged disposable income, retained earnings and other wealth also have a significant impact on consumption. Feldstein estimates the overall impact of Social Security wealth as a 50\% reduction in aggregate savings. 
"The implication that Social Security halves the rate of personal saving is startling but not unreasonable. For middle and low-income families, Social Security is a complete substitute for a substantial rate of private saving. The asset substitution effect is, therefore, likely to be very significant."

The results of Feldstein's study did not go unchallenged. Leimer and Lesnoy (1982), Barro (1978), and Darby (1979) each criticized Feldstein's analysis for omission of relevant variables, measurement errors, or inappropriate definitions of Social Security wealth. ${ }^{1}$ Each also finds little support for effects the size that Feldstein reported in 1974. Feldstein (1996) takes to heart these criticisms of his earlier work and tests for the impact of the Social Security wealth variable using his own preferred specification and those suggested by Barro. In addition, the data set includes twenty-one additional observations, for the years since the original Feldstein (1974) study. He again finds a large reduction in private savings resulting from the Social Security program and concludes that his estimates are robust to alternative specifications of the consumption expenditure equation.

In all of the foregoing literature, however, wealth is assumed to have a constant marginal impact on consumption. The extant theoretical literature often assumes that preferences are homothetic to derive a "solved out" consumption function. Unfortunately, both income and assets have a constant marginal impact in the "solved out" consumption function; this function also has no intercept. ${ }^{2}$ Non-homothetic preferences, while not generally allowing the researcher to derive an explicit consumption function, imply that the effect of assets on consumption varies with the level of assets. ${ }^{3}$ In our empirical work below, we allow the marginal effect of Social Security and other wealth to vary with the level of that wealth.

\footnotetext{
${ }^{1}$ Esposito (1978) reviews the original Fieldstein (1974) study as well as Barro (1978), Darby (1978) and Munnell (1974).

${ }^{2}$ Barro (1978) estimates such a function, finding no evidence that Social Security reduces savings.

${ }^{3}$ Attansio and Weber (1995) find support for non-homothetic preferences in the context of estimating a consumption function.
} 
John Muellbauer and Ralph Lattimore (1995) note that "most macro modelers approximate" the aggregate consumption function using a log-log specification. This allows the marginal effect of assets on consumption to vary with the level of assets. Muellbauer and Lattimore prefer a specification which induces the ratio of assets to income as an explanatory variable and the log of consumption as the dependent variable. ${ }^{4}$ Neither Feldstein nor his critics use either of these specifications, relying on a linear approximation instead.

Muellbauer and Lattimore (1995) also discuss theoretical reasons why the marginal propensity to consume out of wealth is not constant. These explanations imply that as the age distribution of the population changes, it is likely that the MPC out of assets in the aggregate consumption function will change as well. ${ }^{5}$ Unfortunately, some effects raise the MPC out of assets, others reduce it. If those effects tending to raise the MPC out of assets are greater, then as the population ages the marginal propensity to consume out of wealth will rise. In other words, a dollar increase in Social Security wealth today would engender more additional consumption spending than a dollar of Social Security wealth in the past. Said differently, the effect of Social Security wealth on private savings should be greater now than before. If the dampening effects dominate, then the marginal propensity to consume out of assets should exhibit a decline over time.

\section{Empirical Results}

In this section we report the results of several alternative specifications of the aggregate consumption function. Data for the Social Security wealth and other wealth variables come from the appendix to Feldstein (1996). Disposable income and consumption are taken from the Survey of Current Business. Table 1

\footnotetext{
${ }^{4}$ They note that this approach makes it easier to disaggregate assets by liquidity, something "which would be unsatisfactory" in the log-log specification.

${ }^{5}$ Munnell (1974) does something similar to this by interacting disposable income with the labor force participation rate of men over 65. She argues that this variable captures the "induced retirement effect". On the other hand, her estimate, obviously, does not capture the effects of the age distribution on the marginal propensity to consume (or save) out of assets. Moreover, in her post-war sample this variable is never significantly different from zero.
} 
reports descriptive statistics for these variables in per capita terms. The fraction of the population over 65 comes from The Economic Report of the President, 1996.

Table 2 shows regression results for the full sample from 1930 to $1992 .{ }^{6}$ Like Feldstein (1996) we omit the war years 1941-1946 from the full sample. Each regression has been estimated using the HildrethLiu procedure to correct for first order autocorrelation in the residuals. The base equation of Feldstein (1996) is in the first column; our replication of his results is in the second column. ${ }^{7}$ Regression results from five alternative specifications make up the last five columns of the table. We have also included the estimated value of the autocorrelation coefficient for each model.

The important conclusion to draw from this table is that Feldstein's results are not robust to our straight-forward alternative specifications. Model one allows the marginal impacts of household wealth and Social Security wealth to vary with their respective levels by including the square of each as additional regressors. The Feldstein (restricted) model can be rejected in favor of the unrestricted Model 1 which allows for these varying marginal impacts of household and Social Security wealth on consumption. The F-statistic for this test is 4.362 , the critical value of $\mathrm{F}$ is 3.23 at the $95 \%$ level. The marginal propensity to consume out of Social Security wealth, indeed of non-Social Security wealth too, rises as wealth rises. This result is consistent with the precautionary savings literature which suggests that as wealth rises, the propensity to save declines.

Model two imposes the restriction that both Social Security wealth and other household wealth have the same constant marginal impact on consumption. This restriction cannot be rejected, the F-statistic for this test is 1.056 compared to the critical value of 4.04. In other words, the data reject the Feldstein hypothesis

\footnotetext{
${ }^{6}$ Table 3 presents results from the post-war sample. Since these are nearly identical to those of the full sample we make no further reference to Table 3.

${ }^{7}$ The variables in our regressions are thousands of 1987 dollars per capita. We express population in millions of persons, explaining why our estimated intercept term differs by a factor of 1000 from Feldstein's. The small differences in the point estimates may be due to this rounding of the population variable.
} 
that Social Security wealth and all other wealth have differential impacts on aggregate consumption behavior in a linear specification. We interpret this as evidence that the marginal propensity to save out of Social Security wealth is not different than the (weighted) average of the marginal propensities to consume out of other pension wealth, housing stock, IRAs, savings accounts and so on. Moreover, aggregating wealth and allowing for a variable marginal effect, by introducing the square of total wealth as a regressor as in model 3 , is a better specification than including aggregate wealth alone. ${ }^{89}$ That is, a varying marginal propensity to consume out of all assets is preferred by the data to a constant marginal impact.

Models 4 and 5 are semi-log specifications consistent with the discussion in Muellbauer and Lattimore (1995). The upshot of these regressions is once again a rejection of distinct marginal propensities to consume out of Social Security and non-Social Security wealth. Interestingly, because of the near constancy of the average propensity to consume (consumption/disposable income), the marginal propensity to consume out of assets from this specification is, for practical purposes, constant. However, the effect is less than half that suggested by Feldstein (1996).

The tests reported above reject the constant marginal impact imposed by Feldstein's linear aggregate consumption function, an indication that preferences are not homothetic or that age, bequest motives, and/or uncertainty influence the manner in which wealth affects consumption. To assess the effect of an additional dollar of Social Security wealth one must compute the marginal impact of Social Security wealth at every level of wealth. Using the coefficients of Model 1, the marginal impact of Social Security wealth is $\mathrm{dc} / \mathrm{d}(\mathrm{SSW})=.00037+2 * .00044 *(\mathrm{SSW})$. Over the post war period, the marginal propensity to consume out

\footnotetext{
${ }^{8}$ Model three is not completely general in that it imposes equal coefficients on Social Security wealth squared and all other wealth squared, and a zero coefficient on wealth interacted with Social Security wealth. This fully general model is rejected in favor of Model two. The F statistic is 1.7121, the critical value is 2.80 . Tested against this general specification, the Feldstein model is rejected.

${ }^{9}$ Adding to models 1 and 3, respectively, the unemployment rate interacted with disposable income, as suggested by Barro (1978), does not alter either the conclusion that the marginal impact of wealth on consumption varies as wealth changes nor the conclusion that Social Security wealth and household wealth have identical marginal impact.
} 
of Social Security wealth ranges from .0089 in 1947 to .026 in 1972 to .043 in 1992 . Under the specification of Model 1, then, the effect of Social Security wealth on consumption has risen over time and is now about $50 \%$ larger than that estimated by Feldstein.

On the other hand, the marginal impact of Social Security wealth, using the coefficients from Model 3 , is dc/d $(\mathrm{W}+\mathrm{SSW})=-.0088+2 * .00014 *(\mathrm{~W}+\mathrm{SSW}) .{ }^{10}$ At the mean, about $\$ 66$ (thousand) this effect is $\mathrm{dc} / \mathrm{d}(\mathrm{W}+\mathrm{SSW})=.0097$, implying that an additional dollar of wealth, either Social Security or from any other source, raises spending by about one cent. Note that this is about one third of the effect Feldstein finds for every year. We have made this calculation for each of the years in our sample.

Figure 1 shows these marginal impacts of wealth on consumption by year based on the estimates of Model 3, excluding the years 1941 - 1946. Note that wealth has a rising marginal impact on consumption over the sample period. Looking only at the years 1947-1972 as studied in Feldstein (1974), one finds an average marginal propensity to consume out of assets of about .006 , or about .6 cents per dollar of additional consumption for each dollar of additional wealth. This is, of course, far smaller than the effect Feldstein found. Examining the full post-war period of 1947-1992, the mean marginal propensity to consume from assets is .012 , or 1.2 cents per dollar of additional wealth. It is only in and after 1985, in fact, that the effect of an additional dollar of assets is to increase consumption by 2 cents or more. And in this period, the maximum effect is 2.4 cents of spending from another dollar of wealth. In other words, the effect that Feldstein finds for each and every year has, in this specification, never been attained in the sample. His estimated effects of Social Security on savings are over estimates. One should bear in mind, however, that the marginal effect is rising.

Finally, we tested the implication that the marginal propensity to consume out of assets varied with the age distribution of the population. We did this in two ways. First, as a rough guess we simply interacted a linear time trend with the value of assets. Since the population has grown older, on average, since the end

\footnotetext{
${ }^{10}$ All variables are measured in thousands of dollars per capita.
} 
of the Second World War, we thought a linear trend would approximate this affect. Second, we introduced the interaction of the wealth variable with the percentage of the population aged 65 or over. The results from the two approaches are very similar, and Figure 2 indicates why. The percentage of the population aged 65 or over has risen almost linearly since 1947.

Estimating the relationship between consumption, disposable income, lagged disposable income, the combined Social Security and other wealth, and that variable interacted with the age variable, one clearly finds support for the hypothesis that the aging of the population raises the marginal propensity to consume out of assets.

$$
\begin{aligned}
& \text { Cons }_{t}=982+.664 Y D_{t}+.035 Y D_{t-1}-.008 \text { Assets }_{t}+.002(\text { Assets } * \% \text { over65) })_{t} \\
& \begin{array}{llll}
(3.2) \quad(9.5) \quad(.55) \quad(-.59) \quad(2.6)
\end{array}
\end{aligned}
$$

T-statistics are in parentheses below the coefficients. The \%over65 ranges from about 7.75 in 1947 to 12.5 in 1992. The marginal propensity to consume out of assets is $-.008+.002 * \%$ over65, approximately .0075 in 1947 and .017 in 1992. Said another way, an additional dollar of assets, whether in the form of Social Security wealth or some other form of wealth, raised consumption by less than a penny immediately after the war but raises it by 1.7 cents or more today. ${ }^{11}$

\section{Conclusion}

In his conclusion, Feldstein (1979) writes

statistical inference in economics should begin by recognizing that all economic models are false. The specifications are inevitably simplified pictures of reality so that the estimated coefficients cannot be interpreted within the framework of traditional statistical inference. As economists, we must learn about the world by examining a variety of

\footnotetext{
${ }^{11}$ We tested this model against models which separated out wealth into Social Security and other wealth with and without the interactions. Each of these less restrictive models was rejected by the data.
} 
estimates, each with its own biases and measurement problems, and trying to draw inferences that take these problems into account.

In this paper we have taken this advice to heart. By looking at several alternative specifications of the aggregate consumption function we have tried to "learn about the world by examining a variety of estimates". What we have found is that the inferences drawn in Feldstein (1996) are not robust to simple alternative specifications. The evidence in this paper suggests that Feldstein's estimates may miss the mark by a considerable margin for most of the post war era under some models. Under another specification, his estimate of the effect of Social Security wealth on savings is an underestimate. We believe these results have two clear implications, one policy related and one methodological. The policy point is simply that whatever the effects of Social Security in the past, current estimates of those effects and, more importantly, the trend in those effects suggests that now and into the future Social Security's consequences for private savings are larger than ever before. The methodological implication is that empirical results from models which are linear approximations (reduced forms) of relationships implied by theory and tested using aggregate data must be interpreted carefully. To truly understand the effects of Social Security, or any other asset, on savings, one must examine individual level data. 
Bibliography

Ando, Albert and Franco Modigliani. 1963. "The 'Life Cycle' Hypotheses of Saving: Aggregate Implications and Tests." American Economic Review 53(1):55-84.

Barro, Robert J. 1974. "Are Government Bonds Net Wealth?" Journal of Political Economy 82(6):1095-1117. . 1978. The Impact of Social Security on Private Saving: Evidence from the U.S. Time Series. American Enterprise Institute.

Browning, Martin and Annamaria Lusardi. 1996. "Household Saving: Micro Theories and Micro Facts," Journal of Economic Literature, 34(4):1797-1855.

Darby, Michael R. 1979. The Effects of Social Security on Income and the Capital Stock. American Enterprise Institute.

Economic Report of the President. 1996. United States Government Printing Office, Washington, D.C.

Esposito, Louis. 1978. "Effect of Social Security on Saving: Review of Studies Using U.S. TimeSeries Data," Social Security Bulletin (May):9-17.

Feldstein, Martin S. 1974. "Social Security, Induced Retirement, and Aggregate Capital Accumulation." Journal of Political Economy 82(5):905-26. . 1996. "Social Security and Saving: New Time Series Evidence." National Tax Journal 49(2):151-164.

Leimer, Dean R. and Selig D. Lesnoy. 1982. "Social Security and Private Saving: New Time-Series Evidence," Journal of Political Economy 90(3):606-629.

Muellbauer, John and Ralph Lattimore. 1995. "The Consumption Function: A Theoretical and Empirical Overview," in Handbook of Applied Econometrics: Macroeconomics, M. Hashem Pesaran and Mike Wickens, editors. Cambridge, MA: Blackwell Publishers Incorporated.

Munnell, Alicia. 1974. "The Impact of Social Security on Personal Saving," National Tax Journal (December):553-567

Thaler, Richard H. 1990. "Saving, Fungibility, and Mental Accounts," Journal of Economic Perspectives, (Winter) 4(1):193-205. 